\title{
NINFAS DE THRAULODES ULMER, 1920 (INSECTA: EPHEMEROPTERA: LEPTOPHLEBIIDAE) OCORRENTES NO ESTADO DO RIO DE JANEIRO, BRASIL.
}

\author{
Elidiomar Ribeiro Da-Silva
}

Biota Neotropica v3 (n2) -http://www.biotaneotropica.org.br/v3n2/pt/abstract?article+BN01803022003

\author{
Recebido em: 11/09/2003 \\ Revisado em: 19/10/2003 \\ Publicado em: 30/11/2003
}
Departamento de Ciências Naturais, Escola de Ciências Biológicas, Universidade Federal do Estado do Rio de Janeiro (http://www.unirio.br). Av. Pasteur, 458 - 4 andar, Urca, CEP 22290-240, Rio de Janeiro, RJ, Brasil. E-mail: labiaqua@ unirio.br. Bolsista de Pesquisa do CNPq (http://www.cnpq.br).

\begin{abstract}
Nymphs of Thraulodes Ulmer, 1920 (Insecta: Ephemeroptera: Leptophlebiidae) from Rio de Janeiro State, Brazil.

An undescribed nymph of Thraulodes, herein called as Thraulodes sp., is described and illustrated based on a specimen from Itatiaia, Rio de Janeiro State, Brazil. Also is described and illustrated the nymph of T. itatiajanus Traver \& Edmunds, 1967. In the nymphal stage both species are diagnosed mainly based on details of the mouthparts, gills, and colour pattern of the abdomen.
\end{abstract}

Key words: Atalophlebiinae; mayflies; aquatic insects; taxonomy; Neotropics.

\section{Resumo}

Ninfas de Thraulodes Ulmer, 1920 (Insecta: Ephemeroptera: Leptophlebiidae) ocorrentes no Estado do Rio de Janeiro, Brasil.

Uma ninfa inédita de Thraulodes, aqui denominada Thraulodes sp., é descrita e figurada com base em um exemplar procedente de Itatiaia, Estado do Rio de Janeiro, Brasil. Também é descrita e ilustrada a ninfa de T. itatiajanus Traver \& Edmunds, 1967. No estágio ninfal, ambas as espécies são diagnosticadas principalmente com base em detalhes das peças bucais e das brânquias, além do padrão de coloração do abdome.

Palavras-chave: Atalophlebiinae; efemerópteros; insetos aquáticos; taxonomia; Região Neotropical. 


\section{Introdução}

Gênero de distribuição pan-americana, Thraulodes Ulmer, 1920 (Ephemeroptera: Leptophlebiidae: Atalophlebiinae) apresenta sua maior diversidade na Região Neotropical (Traver \& Edmunds 1967). Com aproximadamente 45 espécies descritas, é um dos mais ricos da família Leptophlebiidae, sendo dos componentes de maior destaque da fauna bentônica sul-americana (Chacón et al. 1999). Das 25 espécies registradas para a América do Sul, sete ocorrem no Brasil (Ferreira \& Froehlich 1992, Domínguez et al. 2001), sendo que T. itatiajanus Traver \& Edmunds, 1967, descrita a partir de adulto coligido no município de Itatiaia, era a única com ocorrência registrada no Estado do Rio de Janeiro (Traver \& Edmunds 1967). No presente trabalho são descritas uma ninfa não associada a qualquer espécie conhecida de Thraulodes, também procedente de Itatiaia, além da até então desconhecida ninfa de $T$. itatiajanus.

O presente estudo é parte integrante do plano de trabalho "Leptophlebiidae (Insecta: Ephemeroptera) do Estado do Rio de Janeiro" (Edital Universal - CNPq), que por sua vez está inserido no projeto institucional "Estudos taxonômicos e biológicos de insetos da ordem Ephemeroptera de diferentes regiões do Brasil" (UNIRIO).

\section{Material e Métodos}

As descrições aqui realizadas seguem padrões corriqueiros para Leptophlebiidae neotropicais, especialmente Thraulodes (cf. Domínguez 1987, Lopes et al. 2003). Os desenhos foram realizados a lápis, a partir de micrométrica quadriculada acoplada ao microscópio estereoscópico, sendo posteriormente digitalizados e editados em computador. As fotografias foram tomadas a partir de câmera filmadora digital acoplada ao microscópio estereoscópico.

As coordenadas geográficas dos municípios de procedência dos exemplares estudados foram obitidas no sítio http://www.cide.rj.gov.br. As coordenadas geográficas do Parque Nacional da Serra dos Órgãos e do Parque Nacional do Itatiaia foram obtidas no sítio http:// www.parquesnacionais.hpg.ig.com.br. O material estudado encontra-se depositado nas seguintes instituições, ambas vinculadas à Universidade Federal do Rio de Janeiro, Brasil: Departamento de Zoologia, Instituto de Biologia (DZRJ), e Departamento de Entomologia, Museu Nacional (MNRJ).

\section{Resultados e Discussão}

\subsection{Thraulodes sp.}

\subsubsection{Ninfa madura (Figs. 1, 3-25):}

Comprimento do corpo $10 \mathrm{~mm}$; filamentos caudais quebrados. Coloração geral castanho-clara, com marcações castanhas e castanho-escuras (Fig. 1). Cabeça com uma faixa
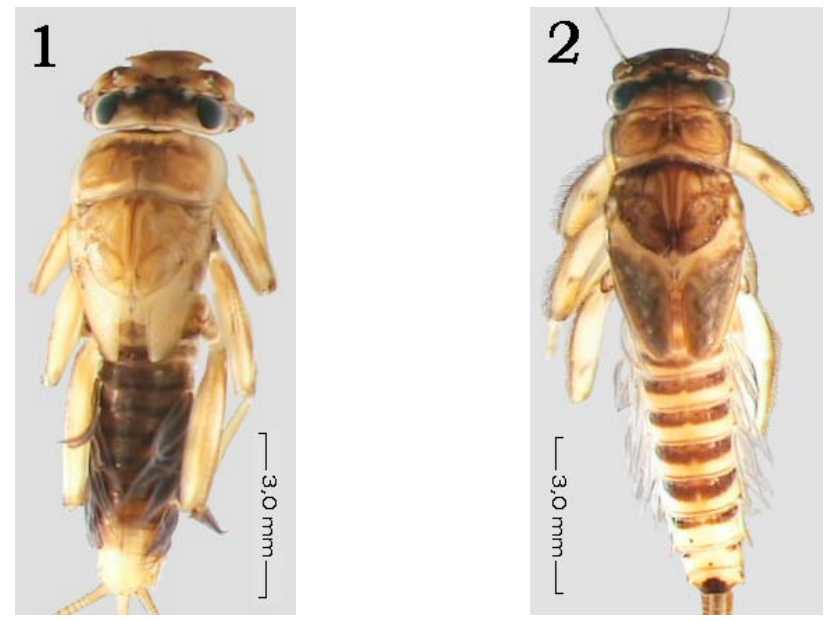

Figura 1. Ninfa madura de Thraulodes sp. (foto E.R. Da-Silva). Figura 2. Ninfa madura de Thraulodes itatiajanus Traver \& Edmunds, 1967 (foto: E.R. Da-Silva)..

irregular castanho-escura entre os olhos e ocelos; área anterior ao ocelo mediano castanho-amarelada. Antenas quebradas no flagelo. Olho negro, porção turbinada (no caso do macho) castanho-escura. Ocelo lateral cinza, ocelo mediano esbranquiçado, parcialmente circundados por uma faixa negra na margem interna. Labro (Figs. 3-4) com uma fileira apical e outra subapical de cerdas curtas; margem anterior reta, com cinco discretas crênulas medianas bastante achatadas; margem lateral angulosa. Mandíbulas (Figs. 512) com tufos de cerdas longas na face dorsal; margem externa com cerdas restritas à metade superior; pequena projeção mediana na margem externa; incisivos mandibulares com pequenos espinhos marginais. Mandíbula direita com três dentículos apicais no incisivo externo e dois no interno; prosteca formada por uma haste basal mais delgada, de onde partem cerdas. Mandíbula esquerda com três dentículos apicais nos incisivos externo e interno; prosteca formada por uma haste basal mais robusta, de onde partem as cerdas. Maxila (Figs. 13-15) com duas fileiras diferenciadas de cerdas apicais, a primeira formada por cerdas longas, em "escova", e a outra formada por cerdas pectinadas, próxima à margem interna, medindo cerca de $1 / 3$ do comprimento da anterior; artículo mediano do palpo maxilar medindo cerca de $3 / 2$ do comprimento do basal, artículo apical medindo cerca de 1/3 do comprimento do mediano; artículos basal e mediano com cerdas marginais diminutas e esparsas; artículo apical de ápice cônico-arredondado, cerdas longas na metade basal da margem externa e tufo de cerdas direcionadas apicalmente, cobrindo a metade interna. Hipofaringe (Figs. 16-17) com língua de ápice pronunciadamente bifurcado, em forma de "U”. Lábio (Figs. 18-20) com glossa de ápice algo acuminado; metade apical da paraglossa com cerdas dorsais direcionadas internamente, margem inferior sem cerdas; artículos basal e mediano aproximadamente de mesmo tamanho, artículo apical diminuto; artículo basal com cerdas 

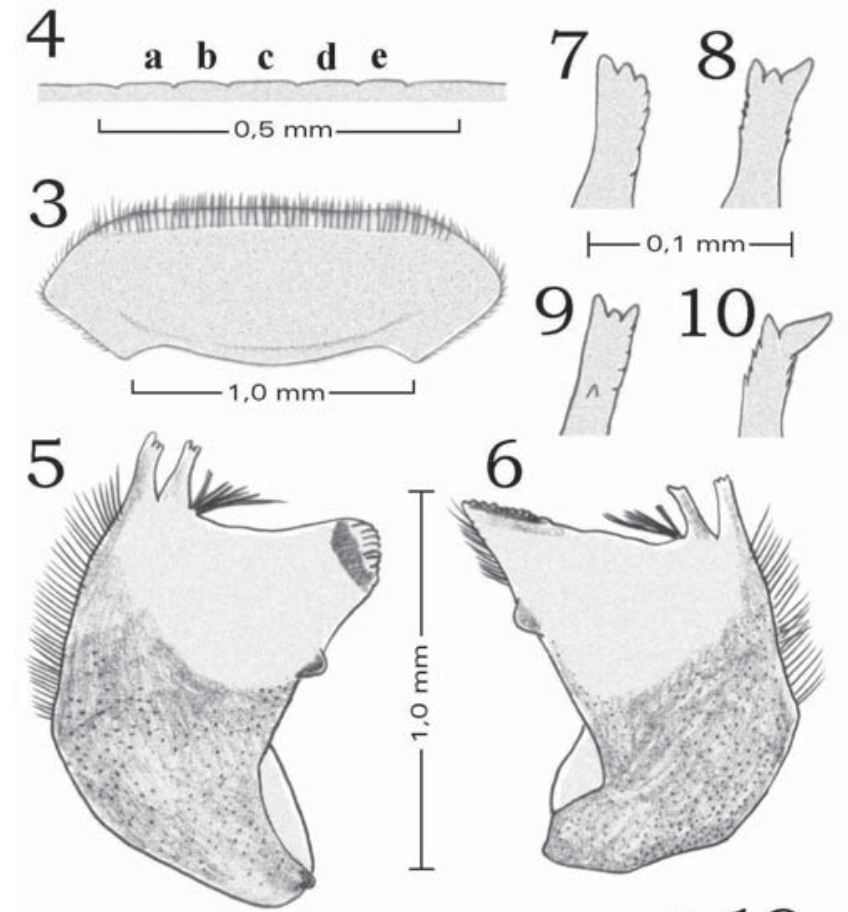

6
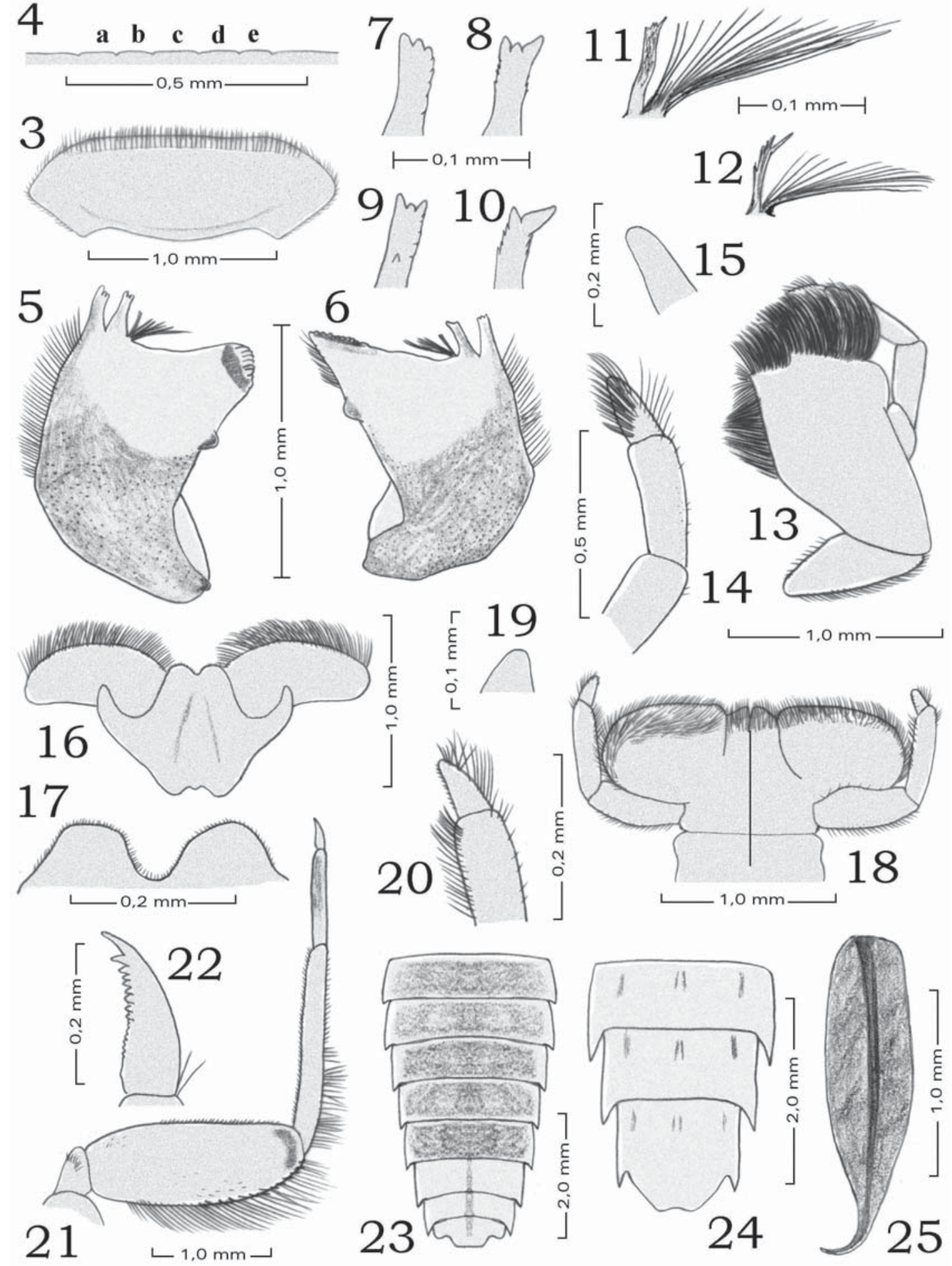

Figuras 3-25. Ninfa madura de Thraulodes sp. 3, labro (dorsal); 4, crênulas anteromedianas do labro (a-e); 5, mandíbula esquerda (dorsal); 6, mandíbula direita (dorsal); 7, ápice do incisivo externo da mandíbula esquerda (dorsal); 8, ápice do incisivo interno da mandíbula esquerda (dorsal); 9, ápice do incisivo externo da mandíbula direita (ventral); 10, ápice do incisivo interno da mandíbula direita (ventral); 11, prosteca da mandíbula esquerda (dorsal); 12, prosteca da mandíbula direita (ventral); 13, maxila esquerda (ventral); 14, artículos basal (parte), mediano e apical do palpo maxilar (ventral); 15, contorno do artículo apical do palpo maxilar (ventral); 16, hipofaringe (ventral); 17, ápice da língua da hipofaringe (ventral); 18, lábio (dorsal à esquerda, ventral à direita); 19, ápice da glossa esquerda (dorsal); 20, artículos mediano (parte) e apical do palpo labial (ventral); 21, perna anterior direita (dorsal); 22, garra tarsal da perna anterior direita; 23, tergitos abdominais (3o a 10o); 24, esternitos abdominais (7o a 9o); 25, lamela dorsal da brânquia direita do 30 segmento abdominal. 


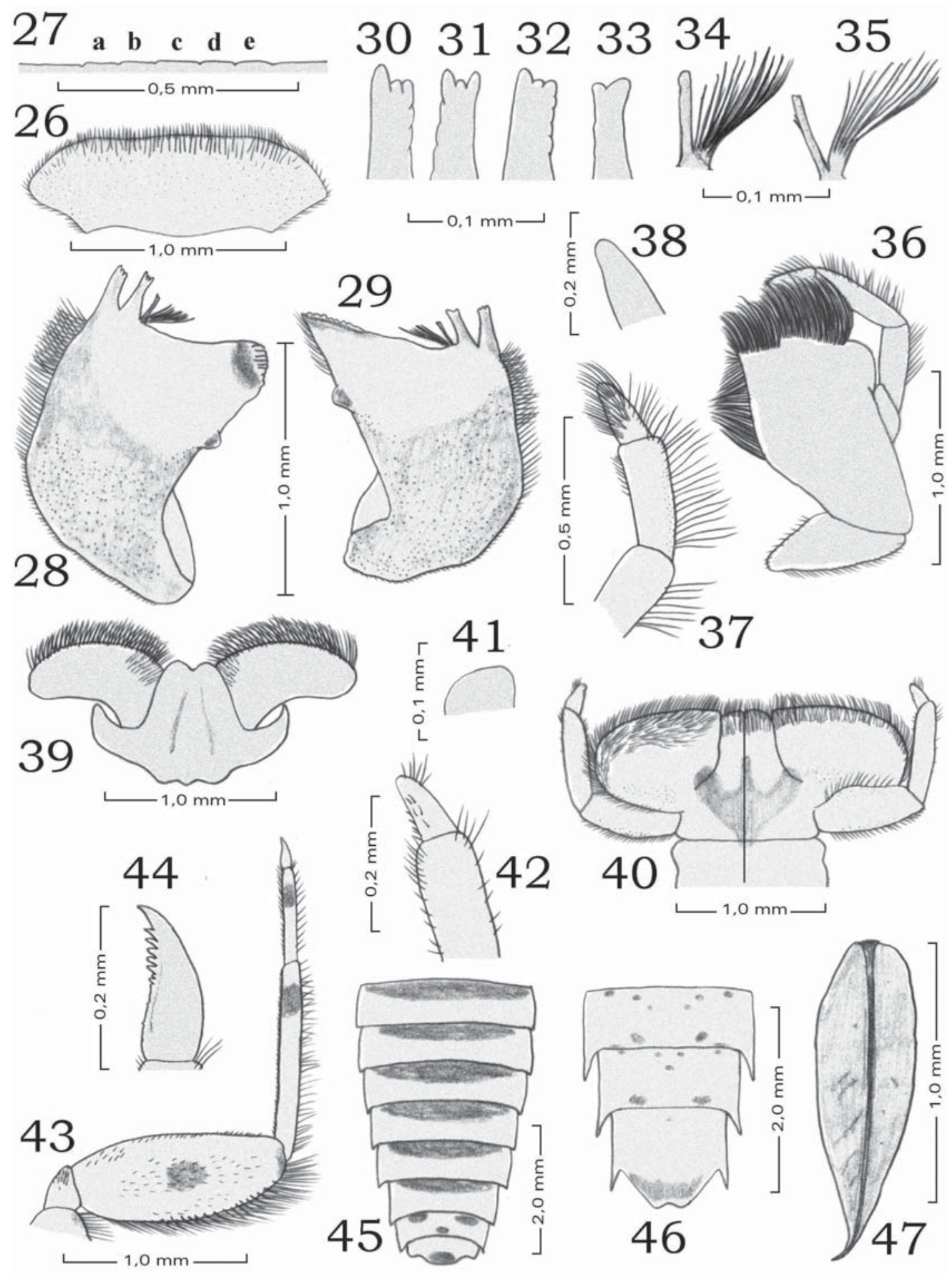

Figuras 26-47. Ninfa madura de Thraulodes itatiajanus Traver \& Edmunds, 1967. 26, labro (dorsal); 27, crênulas anteromedianas do labro (a-e); 28, mandíbula esquerda (dorsal); 29, mandíbula direita (dorsal); 30, ápice do incisivo externo da mandíbula esquerda (dorsal); 31 , ápice do incisivo interno da mandíbula esquerda (dorsal); 32, ápice do incisivo externo da mandíbula direita (ventral); 33, ápice do incisivo interno da mandíbula direita (ventral); 34, prosteca da mandíbula esquerda (dorsal); 35, prosteca da mandíbula direita (ventral); 36, maxila esquerda (ventral); 37, artículos basal (parte), mediano e apical do palpo maxilar (ventral); 38, contorno do artículo apical do palpo maxilar (ventral); 39, hipofaringe (ventral); 40, lábio (dorsal à esquerda, ventral à direita); 41, ápice da glossa esquerda (dorsal); 42, artículos mediano (parte) e apical do palpo labial (ventral); 43, perna anterior direita (dorsal); 44, garra tarsal da perna anterior direita;

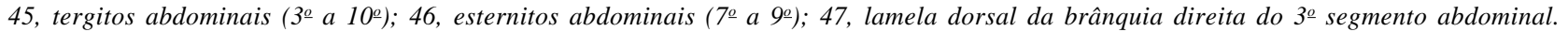


nas margens interna e externa; artículo mediano com cerdas bem desenvolvidas na margem interna, mais concentradas junto ao ápice; artículo apical com cerdas mais longas na margem externa e mais curtas na interna. Tórax dorsalmente salpicado de pequenas manchas mais claras, pouco visíveis. Pronoto com uma faixa transversal irregular castanho-escura, próxima à margem anterior. Mesonoto com ângulos anterolaterais castanho-escuros. Fêmures com ápice escurecido, face dorsal com escassos espinhos curtos, margem interna preenchida por espinhos curtos, margem externa com espinhos e cerdas mais longos; tíbias com metade basal da margem externa portando cerdas longas; tarsos escurecidos apicalmente (Fig. 21); garras (Fig. 22) com dentículos progressivamente maiores em direção ao ápice, culminando em um subapical distintamente maior.

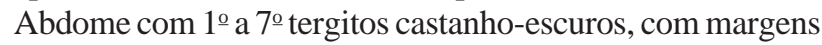
mais claras; $8^{\circ}$ a $10^{\circ}$ tergitos castanho-claros, com uma faixa longitudinal castanha à altura da linha mediana (Fig. 23). Esternitos (Fig. 24) castanho-claros, com duas curtas faixas longitudinais castanhas a cada lado da linha mediana. Brânquias (Fig. 25) com largura máxima medindo cerca de $2 /$ 9 a 1/5 do comprimento, cinza-escuras, com tronco traqueal principal escurecido e demais traquéias pouco visíveis.

\subsubsection{Material estudado.}

Brasil, Estado do Rio de Janeiro, município de Itatiaia, Parque Nacional do Itatiaia, 22²0'S, 4440'W (em um pequeno riacho), 1 ninfa $\bigcirc, 17 / x / 1997$, Equipe do Laboratório de Entomologia/UFRJ col. [DZRJ].

\subsubsection{Comentários.}

Além do fato de Thraulodes sp. não se enquadrar na descrição de qualquer ninfa conhecida do gênero, seu padrão de coloração abdominal não pode ser associado ao de nenhum adulto conhecido de Thraulodes, o que indica que tal espécie possa ser ainda inédita. Não obstante, preferiu-se aqui não nomeá-la até que adultos venham a ser a ela associados. Thraulodes sp. é, aparentemente, bastante semelhante a uma espécie ilustrada e resumidamente descrita (não foi fornecida qualquer informação acerca de coloração, por exemplo) por Demoulin (1955), como “Thraulodes sp.”, também procedente de Itatiaia, principalmente quanto ao formato da glossa e ao padrão de organização das cerdas nas mandíbulas, na hipofaringe e no palpo labial, além da distribuição geográfica. A espécie ilustrada por Demoulin (1955) difere apenas da descrita presentemente por não apresentar crênulas na margem anterior do labro. Thraulodes sp. aqui descrita pode ser diferenciada das demais ninfas do gênero pela seguinte combinação de características: (1) margem anterior do labro reta, com cinco discretas crênulas medianas bastante achatadas (Figs. 3-4); (2) margem lateral do labro angulada (Fig. 3); (3) margem externa das mandíbulas com uma pequena projeção mediana (Figs. 5-6); (4) incisivos mandibulares com pequenos espinhos marginais (Figs. 710); (5) ápice da língua pronunciadamente bifurcado, em forma de "U” (Figs. 16-17); (6) glossa de ápice algo acuminado (Fig. 19); (7) brânquias cinza-escuras, largura máxima medindo cerca de 2/9 a 1/5 do comprimento (Fig. 25); (8) padrão de coloração dos tergitos e esternitos (Figs. 23-24). O padrão morfológico de Thraulodes sp, é aparentemente próximo ao descrito para T. traverae Thew, 1960, espécie que ocorre em Santa Catarina (Brasil) e, possivelmente, no Uruguai (Traver \& Edmunds 1967). Tal suposta semelhança tem sua confirmação dificultada pelo fato da descrição das ninfas dessa última espécie (Traver \& Edmunds 1967: 380-381) não incluir ilustrações. De qualquer forma, T. traverae apresenta brânquias e garras tarsais compatíveis aos aqui descritos para Thraulodes sp., além de também ter cinco crênulas achatadas na margem anterior do labro. Contudo, diferentemente dessa, T. traverae apresenta o labro com um ligeiro recorte mediano e as mandíbulas sem qualquer projeção mediana na margem externa. Com base no formato das brânquias, Thraulodes sp. seria enquadrada no grupo "brunneus", proposto por Allen \& Brusca (1978) na revisão das ninfas de Thraulodes das Américas Central e do Norte, por apresentar lamelas branquiais largas, afilando-se abruptamente em direção ao ápice. Como as demais ninfas conhecidas de Thraulodes (cf. Traver 1944, Edmunds et al. 1976, Domínguez 1987, Ferreira \& Froehlich 1992, Callisto \& Goulart 2000; Lopes et al. 2003), o exemplar de Thraulodes sp. foi registrado em um hábitat ritral de tamanho moderado e forte correnteza, onde se abrigava da força da água posicionando-se sob e entre os seixos no leito do rio.

\subsection{Thraulodes itatiajanus Traver \& Edmunds, 1967}

\subsubsection{Ninfa madura (Figs. 2, 26-47):}

Comprimento do corpo $11 \mathrm{~mm}$; cerco 13-15 mm; filamento mediano 15-16 mm. Coloração geral castanha, com marcações castanho-claras e castanho-escuras (Fig. 2). Cabeça com uma pequena mancha castanho-clara entre o olho, o ocelo lateral e a base da antena; pequena mancha castanho-clara anterior ao ocelo mediano; área entre os olhos, próxima à margem posterior, com marcações castanhas irregulares; área entre os ocelos castanho-escura. Antena medindo cerca de 2,5 vezes o comprimento da cabeça. Olho negro, porção turbinada (no caso do macho) castanho-escura. Ocelo lateral cinza, ocelo mediano cinzaclaro, parcialmente circundados por uma faixa negra na margem interna. Labro (Figs. 26-27) com uma fileira apical e outra subapical, irregular, de cerdas curtas; margem anterior reta, com cinco discretas crênulas medianas bastante achatadas; margem lateral angulosa. Mandíbulas (Figs. 2835) com tufos de cerdas longas na face dorsal; margem 
externa com cerdas longas na metade superior, e curtas na metade inferior; pequena projeção mediana na margem externa; incisivos mandibulares com crênulas na margem interna. Mandíbula direita com três dentículos apicais no incisivo externo e dois no interno; prosteca formada por uma haste basal mais delgada, de onde partem cerdas. Mandíbula esquerda com três dentículos apicais nos incisivos externo e interno; prosteca formada por uma haste basal mais robusta, de onde partem as cerdas. Maxila (Figs. 36-38) com duas fileiras diferenciadas de cerdas apicais, a primeira formada por cerdas longas, em "escova", e a outra formada por cerdas pectinadas, próxima à margem interna, medindo cerca de 1/3 do comprimento da anterior; artículo mediano do palpo maxilar medindo cerca de $2 / 3$ do comprimento do basal, artículo apical medindo cerca de 1/3 do comprimento do mediano; artículos basal e mediano com cerdas longas na margem externa; artículo mediano com cerdas curtas na metade apical da margem interna; artículo apical de ápice cônico-arredondado, cerdas longas na metade basal da margem externa e tufo de cerdas direcionadas apicalmente, cobrindo a metade interna. Hipofaringe (Fig. 39) com língua de ápice fendido, em forma de "V"; base da superlíngua com cerdas ventrais. Lábio (Figs. 40-42) com glossa de ápice ligeiramente truncado; metade apical da paraglossa com cerdas dorsais direcionadas internamente, cerdas da margem inferior bem desenvolvidas; artículos basal e mediano aproximadamente de mesmo tamanho, artículo apical diminuto; artículo basal com cerdas nas margens interna e externa; artículo mediano portando poucas cerdas marginais, sendo diminutas em toda a sua extensão e maiores junto ao ápice; artículo apical com cerdas concentradas na extremidade apical da margem externa e pequenos espinhos junto à margem interna. Tórax dorsalmente salpicado de pequenas manchas castanhoclaras. Pronoto com uma faixa sinuosa castanho-escura, transversal, próxima à margem posterior; margem lateral castanho-clara. Mesonoto com uma faixa longitudinal castanho-clara, a cada lado da linha mediana. Pernas (Fig. 43) castanho-claras; trocanteres com uma mancha castanha apical; fêmures com uma mancha castanha mediana e outra, menor, apical, face dorsal e margem interna com espinhos curtos, margem externa com espinhos e cerdas mais longos; tíbias e tarsos com uma faixa transversal castanha subapical; garras (Fig. 44) com dentículos progressivamente maiores em direção ao ápice, culminando em um subapical distintamente maior. Abdome com tergitos castanho-escuros anteriormente, castanho-claros posteriormente, 9으 e $10^{\circ}$ tergitos com mancha castanho-escura mediana, próxima à margem posterior (Fig. 45). Esternitos (Fig. 46) castanhoclaros, $1^{\circ}$ a $8^{\circ}$ esternitos com três pequenas manchas castanho-escuras a cada lado da linha mediana ( o par mais posterior pode estar fusionado, originando uma mancha única), sendo que o conjunto aparentemente representa o esboço de uma faixa transversal sinuosa; pequena mancha castanha a castanho-escura posterior, a cada lado da linha mediana; 9o esternito com margem posterior castanha. Brânquias (Fig. 47) com largura máxima medindo cerca de 1/ 4 do comprimento, cinzentas, com tronco traqueal principal escurecido e demais traquéias pouco visíveis.

\subsubsection{Material estudado.}

Brasil, Estado do Rio de Janeiro - município de Angra dos Reis, $23^{\circ} 00^{\prime} S, 44^{\circ} 19^{\prime} \mathrm{W}$, Bracuí, tributário do Rio Bracuí (1 ninfa $\delta^{\wedge}, 18 / x / 2000$, A.H. Araújo \& J.L. Nessimian col.); município de Itatiaia, 22²9’S, 44³3’ W, Fazenda Aleluia, Rio Campo Belo (1 ninfa \& , 28/ix/1997, F.F. Salles col.; 1 ninfa $\delta$ e 2 ninfas 9 ○, iv/1999, E.R. da Silva col.; 2 ninfas o $\delta$ e 4 ninfas $q$ ๆ 12/vi/2000, C.N. Francischetti col.);

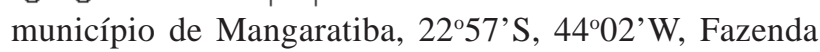
Batatal, Rio Santo Antônio (1 ninfa ₹, 24/ii/2001, C.N. Francischetti col.); município de Nova Friburgo, 22¹6'S, 42³1'W, Caledônia, Rio Caledônia (perto do Hotel Caledônia Inn) (2 ninfas 9 , 01/xii/1991, E.R. da Silva \& A.M. Sanseverino col.); município de Parati, 23ำ13'S, 44²4' W, Estrada Parati-Ubatuba, Piscina do Amor (1 ninfa 9 , 01/vi/ 1985, M.C.C. de Pinna col.) [DZRJ]; município de Teresópolis, Parque Nacional da Serra dos Órgãos, 22 28' S, 43ํ0' W (1 ninfa $\delta$ e 2 ninfas 9 千 $17 /$ iii/1991, S.M. Pereira col.) [MNRJ].

\subsubsection{Comentários.}

T. itatiajanus foi descrita com base em uma imago macho procedente do Parque Nacional do Itatiaia (Traver \& Edmunds 1967). As ninfas aqui descritas são associadas a essa espécie com base no tamanho corporal, na distribuição geográfica e no padrão de coloração do abdome, especialmente dos esternitos, características compatíveis com a descrição do adulto (cf. Traver \& Edmunds 1967). T. itatiajanus parece ser coespecífica a uma ninfa resumidamente descrita e ilustrada por Traver \& Edmunds (1967) como "Thraulodes sp.", de Águas de Prata, Estado de São Paulo. As poucas ilustrações relativas a essa espécie - labro e mandíbula esquerda (Traver \& Edmunds 1967: 395) - ratificam essa possibilidade. T. itatiajanus pode ser diferenciada das demais espécies de Thraulodes conhecidas no estágio ninfal pela seguinte combinação de características: (1) margem anterior do labro reta, com cinco discretas crênulas medianas bastante achatadas (Figs. 2627); (2) margem lateral do labro angulosa (Fig. 26); (3) margem externa das mandíbulas com cerdas curtas na metade inferior e uma pequena projeção mediana (Figs. 28-29); (4) incisivos mandibulares com crênulas marginais (Figs. 3033); (5) artículos basal e mediano do palpo maxilar com cerdas 
longas na margem externa, artículo apical com cerdas longas na metade basal da margem externa e tufo de cerdas direcionadas apicalmente, cobrindo a metade interna (Fig. 37); (6) margem inferior da paraglossa com cerdas bem desenvolvidas (Fig. 40); (7) artículo mediano do palpo labial com poucas cerdas marginais, sendo diminutas em toda a sua extensão e maiores junto ao ápice (Fig. 42); (8) artículo apical do palpo labial com cerdas concentradas na extremidade apical da margem externa e pequenos espinhos junto à margem interna (Fig. 42); (9) largura máxima das brânquias medindo cerca de 1/4 do comprimento (Fig. 47); (10) padrão de coloração dos tergitos e esternitos (Figs. 4546). Levando-se em conta que a grande maioria das ninfas conhecidas de Thraulodes não tem as peças bucais detalhadamente descritas, com exceção ocasional do labro e da mandíbula esquerda, torna-se difícil a comparação de $T$. itatiajanus com as demais espécies do gênero. Com base no formato das brânquias, a espécie seria enquadrada no grupo "brunneus", proposto por Allen \& Brusca (1978) na revisão das ninfas de Thraulodes das Américas Central e do Norte, por apresentar lamelas branquiais largas, afilandose abruptamente em direção ao ápice. Com relação ao padrão de coloração abdominal, o de T. itatiajanus é ligeiramente semelhante ao de T. salinus Kilgore \& Allen, 1973, do Arizona, Estados Unidos da América (Allen \& Brusca 1978), que também apresenta a parte anterior dos tergitos escurecida. Contudo, essa última espécie foi enquadrada por aqueles autores no grupo "gonzalesi", por apresentar brânquias estreitas, afilando-se progressivamente em direção ao ápice (Allen \& Brusca 1978: 415). As informações acerca de hábitat e meso-hábitat de ocorrência das ninfas de T. itatiajanus são, em geral, as mesmas descritas anteriormente para Thraulodes sp. T. itatiajanus foi registrada em riachos de tamanho moderado e forte correnteza, onde os exemplares abrigam-se da força da água posicionando-se sob e entre os seixos no leito do rio. As ninfas coligidas no Rio Caledônia foram obtidas trechos com acúmulo de material orgânico alóctone. A ocorrência da espécie nos municípios fluminenses de Angra dos Reis, Mangaratiba, Nova Friburgo, Parati e Teresópolis é pela primeira vez registrada.

\section{Agradecimentos}

Ao Conselho Nacional de Desenvolvimento Científico e Tecnológico (CNPq), pelo financiamento parcial do presente trabalho. Ao Prof. Dr. Jorge Luiz Nessimian (Universidade Federal do Rio de Janeiro), ao Prof. Dr. Alcimar do Lago Carvalho (Universidade Federal do Rio de Janeiro), ao Dr. Darcílio Fernandes Baptista (Instituto Oswaldo Cruz), ao Prof. Dr. José Roberto Pujol-Luz (Universidade de Brasília) e ao Dr. Carlos Rafael Lugo-Ortiz (San José, Porto Rico), pela leitura crítica do manuscrito. Ao Prof. Dr. Paulo Sérgio Fiuza Ferreira e ao Prof. Dr. Raul Narciso Guedes (Universidade Federal de Viçosa), pela permissão de uso de equipamento para a realização das fotografias.

\section{Referências Bibliográficas}

ALLEN, R.K. \& BRUSCA, R.C. 1978. Generic revisions of mayfly nymphs II. Thraulodes in North and Central America (Leptophlebiidae). Can.Ent. 110:413-433.

CALLISTO, M. \& GOULART, M.D.C., 2000. Phoretic association between Nanocladius (Plecopteracoluthus) sp. (Chironomidae: Diptera) and Thraulodes sp. (Leptophlebiidae: Ephemeroptera). An.Soc.Ent.Bras. 29(3):605-608.

CHACÓN, M.M.; SEGNINI, S. \& DOMÍNGUEZ, E., 1999. Three new species of Thraulodes (Ephemeroptera: Leptophlebiidae: Atalophlebiinae) from Venezuela. Aquat.Insects 21(4):249-257.

DEMOULIN, G. 1955. Une mission biologique belge au Brésil. Éphéméroptères. Bull.Inst.r.Sci.Nat.Belg. 31(20):1-32.

DOMÍNGUEZ, E. 1987. El género Thraulodes (Ephemeroptera: Leptophlebiidae) en la República Argentina. Acta Zool.Lilloana 39:47-65.

DOMÍNGUEZ, E., HUBBARD, M.D., PESCADOR, M.L. \& MOLINERI, C. 2001. Checklist of the Ephemeroptera of South America [edition date 14 October 2001]. URL http:/ /www.famu.org/mayfly/sacat.html.

EDMUNDS, G.F., JENSEN, S.L. \& BERNER, L. 1976. The mayflies of North and Central America. University of Minnesota Press, Minneapolis.

FERREIRA, M.J.N. \& FROEHLICH, C.G. 1992. Estudo da fauna de Ephemeroptera (Insecta) do Córrego do Pedregulho (Pedregulho, SP, Brasil) com aspectos da biologia de Thraulodes schlingeri Traver \& Edmunds, 1967. Revta bras.Ent. 36(3):541-548.

LOPES, M.J.N., FROEHLICH, C.G. \& DOMÍNGUEZ, E. 2003. Description of the larva of Thraulodes schlingeri (Ephemeroptera, Leptophlebiidae). Iheringia, Sér.Zool. 93(2):197-200.

TRAVER, J.R. 1944. Notes on Brazilian mayflies. Bolm Mus.Nacional, N.S. 22:1-53.

TRAVER, J.R. \& EDMUNDS, G.F. 1967. A revision of the genus Thraulodes (Ephemeroptera: Leptophlebiidae). Misc.Pub.Ent.Soc.Am. 5:349-404.

Título: Ninfas de Thraulodes do Rio de Janeiro.

Autor: Elidiomar Ribeiro Da-Silva

Biota Neotropica, Vol. 3 ( number 2): 2003

http://www.biotaneotropica.org.br/v3n2/pt/ abstract?article+BN01803022003

Recebido em: 11/09/2003 Revisado em: 19/10/2003

Publicado em: 30/11/2003 - ISSN 1676-0603 